This is a self-archived - parallel published version of this article in the publication archive of the University of Vaasa. It might differ from the original.

\title{
Forecasting ethanol price volatility under structural breaks
}

Author(s): Bouri, Elie; Dutta, Anupam; Saeed, Tareq

Title: $\quad$ Forecasting ethanol price volatility under structural breaks

Year: $\quad 2020$

Version: Accepted manuscript

Copyright (C) Wiley 2020. This is the peer reviewed version of the following article: Bouri, E., Dutta, A. \& Saeed, T. (2020). Forecasting ethanol price volatility under structural breaks. Biofuels, Bioproducts and Biorefining, early view, which has been published in final form at https://doi.org/10.1002/bbb.2158. This article may be used for noncommercial purposes in accordance with Wiley Terms and Conditions for Use of Self-Archived Versions.

Please cite the original version:

Bouri, E., Dutta, A. \& Saeed, T. (2020). Forecasting ethanol price volatility under structural breaks. Biofuels, Bioproducts and Biorefining, early view. https://doi.org/10.1002/bbb.2158 


\title{
Forecasting Ethanol Price Volatility under Structural Breaks
}

\begin{abstract}
The use of ethanol as a vehicle fuel has reduced greenhouse gas emissions significantly. Additionally, the introduction of ethanol has led to a decrease in crude oil prices. Considering the economic and environmental significance of the biofuel markets, a strand of literature investigates the price and volatility dynamics of US ethanol prices. In this paper, in contrast to previous studies, we investigate whether the information on structural breaks plays any dominant role in predicting US ethanol market volatility. Our findings reveal that GARCH models incorporating these breaks improve the prediction of US ethanol market volatility. Furthermore, the persistence of volatility tends to decline when structural breaks are included in the GARCH models. We further note that the influence of good and bad news is properly assessed under such breaks. Our results suggest that ignoring such breaks could mislead the risk assessment procedure for the US biofuel industry.
\end{abstract}

Keywords: US ethanol market; modelling volatility; structural breaks; volatility persistence; GARCH models. 


\section{Introduction}

Over the past few years, the use of ethanol has increased significantly because of its success in reducing the emission of greenhouse gases and minimizing the need for crude oil [1] $]^{1}$ Generating this leading renewable fuel requires one-third less fossil-fuel energy than producing gasoline which in turn curtails the emission rate. Specifically, ethanol decreases greenhouse gas (GHG) emissions by almost $60 \%$ compared to gasoline. Furthermore, the inception of biofuel causes a drop in traditional energy prices $[2]^{2}$.

The dynamics of the ethanol market have been extensively studied in recent literature. Considering the economic and environmental significance of the biofuel industry, a strand of literature investigates the price and volatility dynamics of international ethanol markets. Notable contributions include $[3,4,5,6]$ among others. These studies mainly investigate how global ethanol markets interact with traditional energy sources, biofuel feedstock prices and other allied markets. [3], for example, employ a smooth transition vector error correction model (VECM) to assess the price relationships among the US ethanol, corn, oil, and gasoline prices from 1990 to 2008. The findings reveal a strong long-run linkage between the food and fuel prices. [4] examine the association between biofuel and its feedstock prices for the US and German

\footnotetext{
${ }^{1}$ A recent report, available from the US Energy Information Administration (EIA), shows that fuel ethanol production capacity in the US has reached more than 16 billion gallons per year, or 1.06 million barrels per day (b/d), at the beginning of 2018. Besides, total listed, or nameplate capacity, of operable ethanol plants increased by 5\%-more than 700 million gallons per year-between January 2017 and January 2018.

${ }^{2}$ As [6] indicates: 'Crude oil prices would be approximately 15-40 a barrel higher in the absence of bioethanol production additives'.
} 
markets. The study finds that the US ethanol prices are sensitive to corn price shocks, while German biodiesel prices react significantly to the variations in soybean price index. In addition, [5] explore the connection among crude oil, corn and ethanol markets in the context of United States. Using several econometric models (vector autoregressive, VECM and autoregressive distributed lag), the authors document that both corn and ethanol prices are influenced by crude oil prices and that ethanol market has a significant positive impact on the corn market. The corn market, however, does not affect the ethanol prices. More recently, [6] suggests that corn market uncertainty, measured by corn implied volatility (CIV) index can explain the variation in ethanol prices. The results indicate that the information on CIV index improves the volatility forecasts for the US ethanol prices.

However, none of the above-mentioned articles uses information on structural breaks in ethanol price variance in their analysis of ethanol market risk, although it is now widely accepted that such breaks are frequently observed in energy price volatility [7]. Since structural breaks can lead to an upward bias in estimated volatility persistence [8], the information on these breaks could play a dominant role in estimating the ethanol price risk. As indicated by [6]: 'If structural breaks are not properly taken into account, they can lead to over-persistent GARCH models, affecting volatility forecasts'. [7] document the same.

The objective of this paper is to extend this scarce literature by examining whether taking structural changes into consideration reduces the volatility persistence of the US ethanol price index ${ }^{3}$. Methodologically, we employ the modified iterated cumulative sums of squares (ICSS) algorithm in order to detect possible breaks occurring in the US ethanol market volatility. The

\footnotetext{
${ }^{3}$ We consider the US market, as it is the leading producer of ethanol, accounting for $58 \%$ of global ethanol production.
} 
detected breaks are then introduced to the conditional equations of various GARCH specifications to assess whether GARCH models that incorporate structural breaks in volatility have better forecasting performances than those that do not. Furthermore, a volatility forecast evaluation is assessed based on value-at-risk (VaR).

The main results of this empirical investigation suggest that ignoring such breaks could mislead the risk assessment procedure of the US biofuel industry. Given that precise estimation of ethanol market volatility plays a crucial role in designing global bioenergy policy, our findings are of utmost importance to market participants.

\section{Materials and methods}

\subsection{Data}

The study uses weekly information on the US ethanol price index. Based on the availability of data, our sample period spans June, 2006 to December, 2017. Hence, the sample consists of 600 weekly observations. Figure 1 shows the US ethanol price index, and we observe several downturns which occur after the 2008 global financial crisis and the 2014 crude oil market recession.

\section{Insert Figure 1 around here}

\subsection{GARCH models}

It well documented that GARCH models have the ability and power to model and forecast volatility [9]. The GARCH models adopted include the symmetric GARCH model of [10] and two asymmetric models: The first is the exponential GARCH (EGARCH) model of [11], whereas the second is the threshold-GARCH (TGARCH) model of [12]. 
Before focusing on the various GARCH processes, we first define the conditional mean equation as:

$$
r_{t}=\pi+\phi r_{t-1}+\varepsilon_{t}
$$

where, $r_{t}$ indicates the logarithmic difference for the US ethanol market index at time $t$ and $\varepsilon_{t}$, the noise term, is distributed as a normal variable with zero mean.

Now the GARCH $(1,1)$ process is given by:

$$
h_{t}^{2}=\omega+\alpha \varepsilon_{t-1}^{2}+\beta h_{t-1}^{2}
$$

In Equation (2), $\omega, \alpha$ and $\beta$ denote the GARCH coefficients, $h_{t}^{2}$ is the conditional variance at time $t, \varepsilon_{t-1}^{2}$ stands for the shocks at time $t-1$. For the GARCH $(1,1)$ process, the persistence of volatility is measured as $\alpha+\beta$.

The TGARCH model is defined as:

$$
h_{t}^{2}=\omega+\alpha \varepsilon_{t-1}^{2}+\gamma \varepsilon_{t-1}^{2} S_{t-1}+\beta h_{t-1}^{2}
$$

where, $S_{t-1}$ refers to a binary variable which is 1 when $\varepsilon_{t-1}$ is negative and 0 elsewhere.

For the TGARCH specification, asymmetry in volatility exists if the null hypothesis $\mathrm{H}_{0}: \gamma=0$ is not true. For this approach, volatility persistence is measured as $\alpha+\beta+1 / 2 \gamma$. Next, the EGARCH model assumes the following form:

$$
h_{t}^{2}=\omega+\alpha\left|\frac{\varepsilon_{t-1}}{h_{t-1}}\right|+\gamma \frac{\varepsilon_{t-1}}{h_{t-1}}+\beta h_{t-1}^{2}
$$


In Equation 4, $\gamma$ refers to the asymmetric parameter. For the EGARCH process, the persistence of volatility is given by $\beta$.

\subsection{Detecting structural breaks}

We apply the iterated cumulative sum of squares (ICSS) algorithm [13] to identify multiple breaks in the unconditional variance of the US ethanol market. We examine the null hypothesis of no breaks at the $5 \%$ level of significance.

In order to consider the breaks, we extend Equation (2) as follows:

$$
h_{t}^{2}=\omega+\varphi_{1} D_{1}+\cdots+\varphi_{n} D_{n}+\alpha \varepsilon_{t-1}^{2}+\beta h_{t-1}^{2}
$$

In Equation (5), $D_{1}, \cdots, D_{n}$ indicate a set of $n$ binary variables taking the value 1 for the break periods and 0 otherwise. We apply a similar approach to the other GARCH specifications.

\subsection{Forecast evaluation}

In this section, we investigate whether the GARCH models incorporating structural changes improve the prediction of the US ethanol market volatility. In order to reach our goal, the following regression model is estimated:

$$
\sigma_{t+1}^{2}=a+b \sigma_{f, t}^{2}+\xi_{t}
$$

Within this framework, $\sigma_{t+1}^{2}$ stands for the realized variance of biofuel prices at time $t+1$ and $\sigma_{f, t}^{2}$ refers to the estimate of ethanol volatility at time $t$. As suggested by [14], we consider the squared excess returns in order to gauge the realized variance of ethanol prices. Additionally, $\sigma_{f, t}^{2}$ is measured by the GARCH forecast. 


\subsection{VaR evaluation}

In this subsection, we conduct a VaR analysis based on both symmetric and asymmetric GARCH models with the aim of assessing whether the incorporation of structural breaks in the conditional variance of ethanol prices leads to more accurate estimates of the VaR. The latter, computed at $5 \%$ quantiles, is given by:

$$
V a R=\mu+t \cdot \sqrt{h_{t}^{2}}
$$

Using the failure ratio of $[15,16]$, we then compare the VaR of GARCH models with structural breaks to the VaR of GARCH models free of structural breaks. Any evidence that the VaR based on the GARCH model with structural breaks is lower than the VaR of the GARCH model free of structural breaks would indicate the utility of taking into account structural breaks, given that it would lead to a more accurate VaR measure.

\section{Results and discussion}

\subsection{Results of GARCH models}

The outcomes of the baseline GARCH model and the extended model (i.e., GARCH including structural changes) are presented in Table 1. The GARCH coefficients are found to be significant, implying that $\mathrm{ARCH}$ and $\mathrm{GARCH}$ effects exist in the ethanol price data. We find evidence of volatility persistence in the US biofuel market, since $\alpha+\beta \approx 1$. Therefore, today's return could exert substantial impacts on future volatility. That is, the future volatility of ethanol returns could be determined by today's returns. However, the persistence of volatility tends to decline after accounting for structural breaks, as indicated by the parameter values of the extended GARCH process. 


\section{Insert Tables 1-4 around here}

The findings shown in Tables 2 and 3, which display the estimates of the EGARCH and TGARCH approaches, confirm that ethanol market variance is substantially affected by structural breaks. For example, for each asymmetric process, volatility persistence has a tendency to decrease when structural breaks are included in the GARCH models. Moreover, the results do not indicate asymmetric behaviour of ethanol market volatility, as the $\gamma$ coefficient in each case appears to be insignificant. Thus, both positive and negative shocks seem to have a similar effect on ethanol price variance. More importantly, the parameter estimating such an effect decreases markedly after allowing for the breaks. Table 4, which shows the impacts of good and bad news on volatility, indicates that when the exponential GARCH process is considered, good news has an impact of 0.1091 for the standard model and 0.0170 for the extended version. The corresponding impacts of bad news are 0.0700 and 0.0532 , respectively. The significance of incorporating structural breaks into the GARCH models is also demonstrated by the log likelihood values and the Akaike and Bayesian information criteria (AIC and BIC), since these estimates appear to be lower for the GARCH models allowing for breaks.

\subsection{Volatility forecasting performance}

The estimates of Equation 6, shown in Table 5, suggest that for GARCH models incorporating structural changes, the values of the $\mathrm{R}^{2}$ statistic tend to increase. In the case of symmetric GARCH specifications, for example, the $\mathrm{R}^{2}$ statistics amount to 0.1067 for the standard model and 0.1852 for the modified model. Similar results are obtained for the other GARCH models. Based on our analyses, we can conclude that, when forecasting the ethanol price variance, the 
occurrence of structural breaks needs to be handled carefully. Overall, the results support that GARCH models including structural breaks improve the prediction of the US ethanol market volatility.

\section{Insert Table 5 around here}

Notably, our findings are consistent with those reported by $[7,17,18]$. These studies also document that structural breaks are frequently observed in financial data, which could mislead the risk assessment process if they are not detected precisely. [7], for instance, show that oil and gold markets interact with each other when structural breaks in variance are taken into account. Such linkage, however, becomes insignificant if these breaks are ignored. In addition, [17] find that accounting for endogenously determined structural breaks within an asymmetric GARCH model reduces the volatility persistence in oil prices. The authors further argue that prior studies have significantly underestimated the impact of news on volatility as they have inadvertently ignored these structural breaks in volatility. More recently, [18] document that econometric approaches, which incorporate both time varying volatility and structural breaks in volatility of stock prices, produce more accurate value-at-risk forecasts than a number of benchmark models. Hence, considering structural breaks in volatility plays a major role in understanding the volatility of financial and commodity markets. Future research could, therefore, replicate earlier studies $[3,4,5,6]$, which ignore the structural changes in ethanol price volatility. Such attempts could improve our knowledge on the risk associated with the US ethanol market.

\subsection{VaR performance}

Table 6 presents the results of the VaR measure and failure ratio. It is clear that the VaR based on the GARCH models with structural breaks is lower than the VaR of the GARCH models free 
of structural breaks. This implies that considering structural breaks when modelling the conditional variance of ethanol prices gives more accurate estimates of the VaR. Practically, this would prevent suboptimal capital allocation and thus avoid redundant capital requirements to manage the risk of ethanol prices.

\section{Insert Table 6 around here}

\section{Conclusions}

The use of ethanol as a vehicle fuel has reduced greenhouse gas emissions significantly. In addition, the introduction of ethanol has led to a decrease in crude oil prices. Considering the economic and environmental significance of the biofuel markets, a strand of literature investigates the price and volatility dynamics of US ethanol prices. In this paper, in contrast to previous studies, we investigate whether the information on structural breaks plays any dominant role in predicting US ethanol market volatility. Our findings reveal that GARCH models incorporating these breaks improve prediction of US ethanol market volatility. In addition, the persistence of volatility and the VaR measure tend to decline when structural breaks are included in the GARCH models. We further note that the influence of good and bad news is properly assessed under such breaks.

These findings may have important implications for ethanol market participants. Investors, for instance, could forecast the future biofuel market trend more precisely, as our results suggest that allowing for structural breaks in ethanol price risk offers better estimates of US ethanol market volatility. It is noteworthy that participants in renewable energy markets not only want to decarbonize their portfolios, but also aim to gain risk-adjusted returns from their investments. That is, investors would try to include those assets in their portfolios, which minimize the 
potential risk and at the same time help them to maintain low-carbon portfolios. To this end, it is important for them to understand the risk linked to renewable energy assets, since proper knowledge on volatility is crucial for portfolio modeling and assessment of time-varying risk. Hence, our outcomes are of utmost importance to investors who want to green their portfolios, as the results are useful for precisely estimating the ethanol market risk.

Policymakers, operating in the biofuel sector, are always in search of effective hedging strategies to dodge the adverse effect of contagious shocks coming from important financial and commodity markets. A true indicator of ethanol price risk is thus required for executing such strategies. The outcomes of current research work might help them achieve such measures. Moreover, as energy markets are frequently experiencing unprecedented volatility caused by various economic and geopolitical news, precise estimates of time-varying volatility are essential for making proper investment decisions. The results of this empirical research may help the decision makers in this regard. Besides, policymakers are extremely interested in knowing how major news (good and bad) impacts ethanol price volatility given that this has a major effect on biofuel policy planning. Our findings are important in such cases as they indicate that both good and bad news have significantly less influence on volatility if structural breaks are accounted for in the model.

The results of our empirical study are important for academics as well. They could, for example, replicate earlier studies which inadvertently ignore the presence of structural breaks in modeling emission price volatility. Such replications could provide a more precise estimate for the US ethanol price risk.

Our study is not free of limitations. For example, we use weekly observations for ethanol market. Future research could consider the presence of breaks and its impact on volatility forecasting 
using high-frequency data. Besides, the Brazilian ethanol prices and the EU biodiesel prices are not included in our analyses. These markets are equally important given that the demand for renewable fuels has increased globally. In addition, it is also crucial to investigate how the ethanol sector interacts with its allied markets (e.g., oil, agriculture etc.) under structural breaks. Future studies could take into account these issues when exploring the volatility of biofuel prices.

\section{References}

[1] de Almeida, L.G.F., da Costa Parrella, R.A., Simeone, M.L.F., de Oliveira Ribeiro, P.C., dos Santos, A.S., da Costa, A.S.V., Guimarães, A.G. and Schaffert, R.E. (2019). Composition and growth of sorghum biomass genotypes for ethanol production. Biomass and bioenergy, 122, 343348.

[2] Renewable Fuels Association (2013) New analysis: ethanol cutting crude oil, gasoline prices, September 23rd. 2013.

[3] Serra, T., Zilberman D., Gil, J.M., Goodwin B.K. (2011). Nonlinearities in the U.S. cornethanol- oil-gasoline price system. Agricultural Economics, 42, 35-45.

[4] Kristoufek, L., Janda, K., Zilberman, D. (2014). Price transmission between biofuels, fuels, and food commodities. Biofuels, Bioproducts and Biorefining, 8, 362-373.

[5] Chiu, F.P., Hsu, C.S., Ho, A., Chen, CC. (2016). Modeling the price relationships between crude oil, energy crops and biofuels. Energy, 109, 845-57.

[6] Dutta, A. (2019). Forecasting Ethanol Market Volatility: New Evidence from the Corn Implied Volatility Index. Biofuels, Bioproducts and Biorefining, 13, 48-54. 
[7] Ewing, B.T., Malik, F. (2013). Volatility transmission between gold and oil futures under structural breaks. International Review of Economics and Finance 25, 113-121.

[8] Hillebrand, E. (2005). Neglecting parameter changes in GARCH models. Journal of Econometrics, 129, 121-138.

[9] Alberg, D., Shalit, H., Yosef, R. (2008). Estimating stock market volatility using asymmetric GARCH models. Applied Financial Economics, 18(15), 1201-1208.

[10] Bollerslev, T. (1986). Generalized autoregressive conditional heteroskedasticity. Journal of Econometrics, 31, 307-327.

[11] Nelson, D.B. (1991). Conditional heteroskedasticity in asset returns: A new approach. Econometrica, 59, 347-370.

[12] Glosten, L., Jagannathan, R., Runkle, D. (1993). On the relation between the expected value and the volatility of the nominal excess return on stocks. The Journal of Finance, 48, 1779-1801.

[13] Inclan, C., Tiao, G.C. (1994). Use of cumulative sums of squares for retrospective detection of changes of variance. Journal of the American Statistical Association, 89(427), 913-923.

[14] Kanas, A. (2013). The Risk-Return Relation and VIX: Evidence from the S\&P 500, Empirical Economics, 44(3), 1291-1314.

[15] Charles, A., Darné, O. (2014). Large shocks in the volatility of the Dow Jones Industrial Average index: 1928-2013. Journal of Banking \& Finance, 43, 188-199.

[16] Bouri, E., Jalkh, N. (2019). Conditional quantiles and tail dependence in the volatilities of gold and silver. International Economics, 157, 117-133.

[17] Ewing, B. T., Malik, F. (2017). Modelling asymmetric volatility in oil prices under structural breaks. Energy Economics 63, 227-223.

[18] Hood, M., Malik, F. (2018). Estimating downside risk in stock returns under structural breaks. International Review of Economics \& Finance, 58, 102-112. 


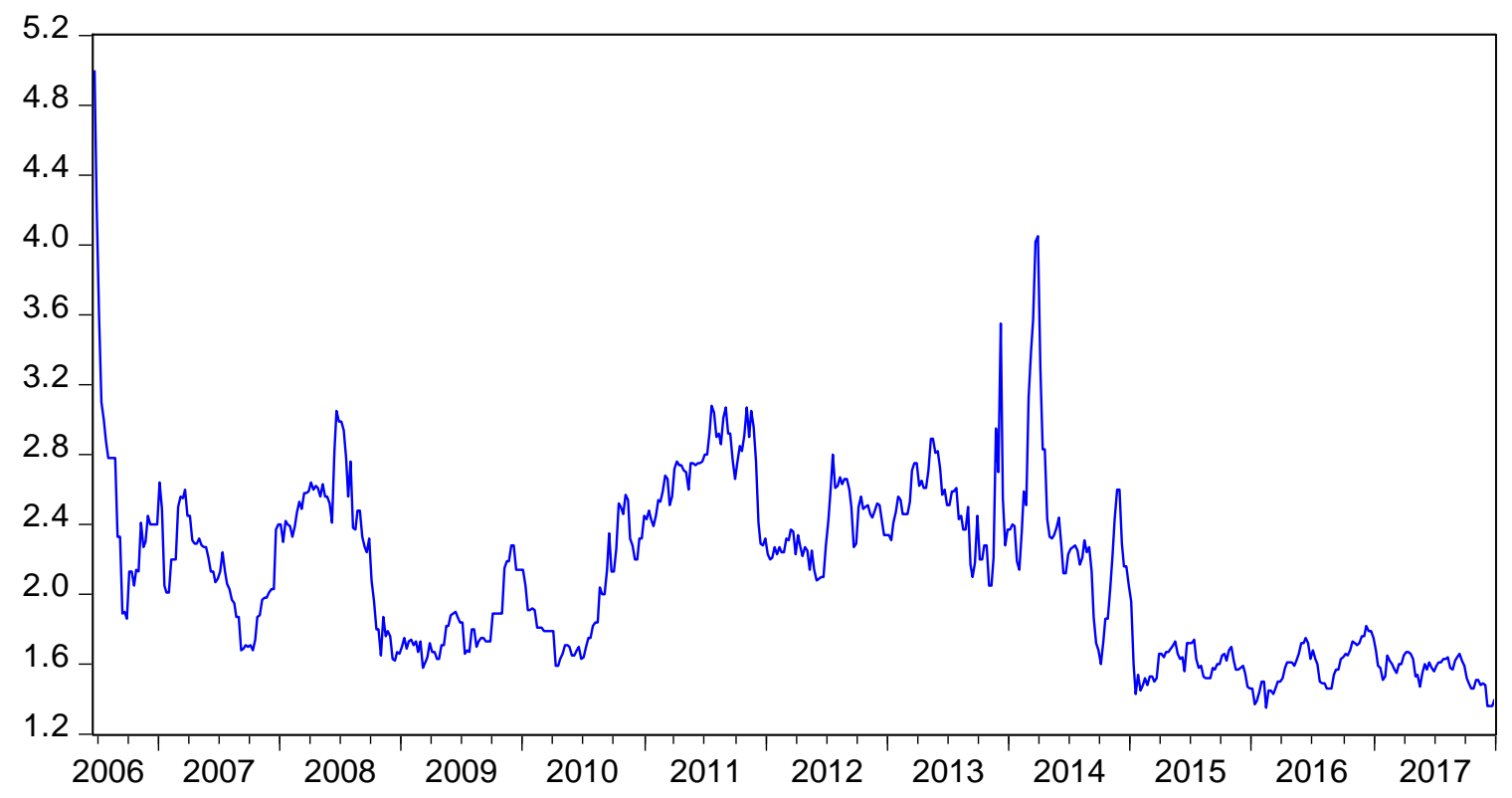

Figure 1: The US ethanol price index 2006-2017 
Table 1: Estimates of GARCH $(1,1)$ model

\begin{tabular}{|c|c|c|c|c|}
\hline \multirow[t]{2}{*}{ Parameters/Models } & \multicolumn{2}{|c|}{ Standard GARCH } & \multicolumn{2}{|c|}{ Extended GARCH } \\
\hline & Estimates & Standard Error & Estimates & Standard Error \\
\hline$\omega$ & $1.2839 * * *$ & 0.3066 & $5.3217 *$ & 2.8144 \\
\hline$\alpha$ & $0.0957 * * *$ & 0.0161 & 0.0363 & 0.0285 \\
\hline$\beta$ & $0.8463 * * *$ & 0.0248 & 0.3838 & 0.3118 \\
\hline Persistence & 0.9420 & & 0.4201 & \\
\hline Log likelihood & -1769.41 & & -1737.14 & \\
\hline AIC & 5.914 & & 5.886 & \\
\hline $\mathrm{BIC}$ & 5.951 & & 5.846 & \\
\hline
\end{tabular}

Notes: $* * * \mathrm{p}<0.01 ; * * \mathrm{p}<0.05 ; * \mathrm{p}<0.1$ 


\section{Table 2: Estimates of TGARCH model}

\begin{tabular}{|c|c|c|c|c|}
\hline \multirow[t]{2}{*}{ Parameters/Models } & \multicolumn{2}{|c|}{ Standard TGARCH } & \multicolumn{2}{|c|}{ Extended TGARCH } \\
\hline & Estimates & Standard Error & Estimates & Standard Error \\
\hline$\omega$ & $1.2170 * * *$ & 0.3030 & $5.2285^{* *}$ & 2.5258 \\
\hline$\alpha$ & $0.1091 * * *$ & 0.0232 & 0.0170 & 0.0355 \\
\hline$\beta$ & $0.8548 * * *$ & 0.0243 & 0.3845 & 0.2849 \\
\hline$\gamma$ & -0.0371 & 0.0336 & 0.0362 & 0.0482 \\
\hline Persistence & 0.9455 & & 0.4196 & \\
\hline Log likelihood & -1769.05 & & -1737.01 & \\
\hline AIC & 5.916 & & 5.823 & \\
\hline $\mathrm{BIC}$ & 5.960 & & 5.896 & \\
\hline
\end{tabular}

Notes: $* * * \mathrm{p}<0.01 ; * * \mathrm{p}<0.05 ; * \mathrm{p}<0.1$ 
Table 3: Estimates of EGARCH model

\begin{tabular}{|c|c|c|c|c|}
\hline \multirow[t]{2}{*}{ Parameters/Models } & \multicolumn{2}{|c|}{ Standard EGARCH } & \multicolumn{2}{|c|}{ Extended EGARCH } \\
\hline & Estimates & Standard Error & Estimates & Standard Error \\
\hline$\omega$ & -0.0054 & 0.0260 & $1.1162 * *$ & 0.5585 \\
\hline$\alpha$ & $0.1808 * * *$ & 0.0210 & 0.0585 & 0.0503 \\
\hline$\beta$ & $0.9602 * * *$ & 0.0215 & $0.4691 *$ & 0.2587 \\
\hline$\gamma$ & 0.0243 & 0.0104 & -0.0574 & 0.0411 \\
\hline Persistence & 0.9602 & & 0.4691 & \\
\hline Log likelihood & -1773.30 & & -1736.73 & \\
\hline AIC & 5.931 & & 5.822 & \\
\hline $\mathrm{BIC}$ & 5.974 & & 5.895 & \\
\hline
\end{tabular}

Notes: $* * * p<0.01 ; * * p<0.05 ; * \mathrm{p}<0.1$. 
Table 4: The impact of news on volatility

$\begin{array}{ll}\text { Standard model } & \text { Extended model }\end{array}$

\section{Panel A: TGARCH model}

\begin{tabular}{lcc}
\hline Bad news & 0.0700 & 0.0532 \\
Good news & 0.1091 & 0.0170 \\
\hline
\end{tabular}

\section{Panel B: EGARCH model}

$\begin{array}{lcr}\text { Bad news } & 0.1565 & 0.1169 \\ \text { Good news } & 0.2051 & 0.0011\end{array}$
Notes: We present the results for asymmetric models only, as the symmetric GARCH model does not allow us to
observe such effects. 
Table 5: Volatility forecasting performance

\begin{tabular}{clllllc}
\hline & GARCH $(1,1)$ & Extended & TGARCH & Extended & EGARCH & Extended \\
& & GARCH $(1,1)$ & & TGARCH & & EGARCH \\
\hline$a$ & 0.4864 & -2.2353 & -8.4079 & 1.1227 & -1.9750 & -0.4428 \\
$b$ & $1.0221 * * *$ & $1.1166^{* * *}$ & $1.4045^{* * *}$ & $0.9656^{* * *}$ & $1.1231^{* * *}$ & $1.0371^{* * *}$ \\
$R^{2}$ & 0.1067 & 0.1852 & 0.1206 & 0.1696 & 0.1236 & 0.1745 \\
\hline
\end{tabular}

Notes: $* * * \mathrm{p}<0.01 ; * * \mathrm{p}<0.05 ;{ }^{*} \mathrm{p}<0.1$. 
Table 6: Results of the VaR measure and failure ratio

\begin{tabular}{lcccccc}
\hline & GARCH (1,1) & Extended & TGARCH & Extended & EGARCH & Extended \\
& & & TGARCH & & EGARCH \\
\hline VaR & -1.993 & -1.985 & -1.997 & -1.995 & -2.003 & -1.998 \\
\hline Failure ratio & $4.557 \%$ & $4.547 \%$ & $4.381 \%$ & $4.377 \%$ & $4.722 \%$ & $4.598 \%$ \\
& & & & & \\
\hline $\begin{array}{l}\text { Notes: The failure ratio reflects the percentage of negative returns smaller than the VaR. The latter is computed at } \\
\text { 5\% quantiles. }\end{array}$
\end{tabular}

